\title{
A High-Resolution Melting Approach for Analyzing Allelic Expression Dynamics
}

\author{
Jiazheng Yuan 1,2, Muhammad Haroon', David \\ Lightfoot $^{2}$, Yvan Pelletier ${ }^{1}$, Qiang Liu ${ }^{3}$, and Xiu- \\ Qing $\mathbf{L i}^{\star * 1}$
}

1Potato Research Centre, Agriculture and Agri-Food Canada, 850 Lincoln Road, P.O. Box 20280, Fredericton, NB, E3B 4Z7, Canada

2Department of Plant, Soil and Agriculture Systems, Southern Illinois University at Carbondale, IL 62901 USA ${ }^{3}$ Guelph Food Research Centre, 93 Stone Road West, Guelph, Ontario, N1G 5C9, Canada

Received 15 August 2008

Revised 1 October 2008

Accepted 4 October 2008

\begin{abstract}
Single nucleotide polymorphisms (SNPs) are single base pair mutations that provide new approaches to studies of allele transcript abundances. High-resolution DNA melting curve (HRM) analysis using a LightScanner (Hi-Res Melting ${ }^{\mathrm{TM}}$ system with Idaho's LC Green) provides postPCR detection of mutations and SNPs in genomic DNA. This study investigated whether the HRM analysis can distinguish alleles among potato (Solanum tuberosum) transcript abundances. Transcript properties of genes encoding seven carbohydrate metabolism enzymes/ proteins in various tissues and cold storage durations were studied. The HRM assay measured differential expression of alleles between different organs, between different storage treatments and stages of tubers from the same variety, and between different varieties with the same treatment. The RT-PCR amplicons were directly sequenced to assist the interpretation of HRM data. The cDNA HRM curves correlated well with the nucleotide polymorphisms of the cDNA sequences and the transcript abundance of alleles and therefore can serve as functional allele activity (FAA) markers. By combining the allelic specificity of HRM with simple PCR design, this technology can be applied to rapidly determine the most active allele of a gene among the cells analyzed.
\end{abstract}

\section{Introduction}

Trait differences among cultivars are mainly due to the inheritance and or expression of different alleles (Foolad and Lin, 1998). Because most genes have multiple alleles, many produce multiple nascent transcripts to respond coordinately to the temporal, spatial, or external stimuli.

${ }^{*}$ For correspondence:

xiu-qing.li@agr.gc.ca; lixiuqing2008@gmail.com

Tel: +1 506-452-4829

Fax: +1 506-452-3316
The melting temperature of a double strand DNA fragment is defined as the temperature where $50 \%$ of the DNA is single stranded (SantaLucia Jr, 1998). The nucleotide CG-pairs have a higher melting temperature tolerance than AT-pairs, and the latter has a higher tolerance than deletions. If an allele has a higher proportion of CG pairs than another allele, the allele shows a higher melting temperature. Melting temperature is one of the characteristics of DNA, and cDNA and can be used in describing the difference (polymorphism) among alleles (Howell et al., 2002; Wittwer et al., 2003). Single nucleotide polymorphisms (SNPs) are single base pair mutations at specific loci. They are the most common type of genetic variation and also evolutionarily conserved (Syvanen, 2001). Therefore, SNP-based markers can be used to facilitate quantitative trait loci (QTL) analysis and trait association studies. High-resolution DNA melting curve analysis has become a robust method to perform genotyping (Montgomery et al., 2007) and provides sensitive detection of mutations, including SNPs.

Gene transcriptional regulation has been studied in several ways, including Northern hybridization (Alwine et al., 1977), real time PCR (Nolan et al., 2006), serial analysis of gene expression (SAGE) (Velculescu et al., 1995), expressed sequence tag (EST) sequencing (Flinn et al., 2005), and microarray analysis (Meyers et al., 2004). Each of these technologies provides a measurement of gene expression with various strengths and shortcomings. Transcriptional changes play a major role in many plant physiological processes. Analysis of transcription abundances allows the inference of coordinated transcription events and organized gene expressions. Dissection of alterations in transcription abundance has provided unique opportunities to study gene function by the comparison of species, tissues, and time durations simultaneously (Schenk et al., 2000; Zhao et al., 2004; lqbal et al., 2005; Journot-Catalino et al., 2006). To detect and distinguish several transcripts sensitively, methods such as fluorescence dye and distinct color labeled oligo DNA probes have been used to detect many transcripts using the real-time PCR approach (Jeong et al., 2007). These spectral approaches usually possess a minimum of two distinct fluorophores to increase specificity. However, the assays are laborious and often do not contain specific or allelic information during the transcript analysis.

A simple approach that can sensitively visualize expressed allelic variants and the transcript abundance dynamics in high throughput using a small amount of RNA is still a challenge. Few current techniques for gene expression assays allow the analysis of transcript abundance regulation in a structural context (Guo et al., 2006). Real-time PCR analysis is another approach, but its resolution often does not reach a single nucleotide level during transcript analysis. The LightScanner is a post-PCR Hi-Res Melting ${ }^{\mathrm{TM}}$ system (Idaho Technology 
Inc, Salt Lake City, UT) for genotyping and mutation scanning. The system has been widely used in genomic DNA genotyping. The LightScanner produces better scanning specificity than current popular real-time Q-PCR instruments (Herrmann et al., 2007). The dsDNA binding dyes LCGreen ${ }^{\circledR}$ Plus offers better sensitivity and specificity in the DNA melting analysis than that of SYBR Green (Wittwer et al., 2003; Herrmann et al., 2006; Herrmann et al., 2007). The HRM approach enabled the detection of RNA editing of chloroplast transcripts by mixing plasmid DNA containing a $\mathrm{C}$ and plasmid DNA containing a $\mathrm{T}$ at the same site in various ratios (Chateigner-Boutin and Small, 2007). Each plant cell has many chloroplasts, chloroplast RNA is expected to be in a higher density than the mRNA density of a nuclear gene. Chloroplast RNA can be quite extensively edited along the transcript molecules and can have a $3.6 \%$ change amino acid sequence identity (Kugita et al., 2003). Therefore, chloroplast RNA HRM assay does not necessarily conclude whether HRM can effectively monitor nuclear gene allele activities and transcript properties.

Here, the LightScanner-based HRM was employed to study potato nuclear gene derived transcript abundance; to infer coordinated transcription events; and to study the allelic dynamics of gene expression within various organs, tissues, genotypes, and treatment. The allelic variants of genes accumulated in temporal and spatially distinct fashions. By combining advances of fluorescence detection with simple PCR design, visualization of allelic expression dynamics was achieved. This technology has potential to monitor allele activation and silencing and to determine the changes of the dominant transcript in genetically heterogeneous cells. Thus, a new platform for the study of the potato transcriptome is demonstrated.

\section{Methods}

\section{Plant materials and primer design}

Potato varieties 'Shepody', 'Atlantic', and 'Superior' were used. For the tissue specific expression of genes, 15 types of tissues of Shepody were studied, which included tuber tissues; perimedulla, vascular ring, cortex, and skin; and different organs of the plants; flowers, fruits, shoot tips, health fully opened leaves, old yellowing leaves, petioles, young stems, young roots, stolons, tiny young tubers, and mature tubers, young leaves, old leaves. For the study on tissue specificity, tissue/organ samples were from Shepody plants growing in the greenhouses. For storage stage gene expression analysis, Atlantic and Superior plants were grown in the field, and the mature tubers were stored at the storage facility $\left(7^{\circ} \mathrm{C}\right)$ at the Potato Research Centre of Agriculture and Agri-Food Canada (Fredericton, NB).

After the preliminary screening, five genes (seven primer pairs) were studied (Table 1), and three genes including acid invertase, acid invertase inhibitor, and ADP-glucose pyrophosphorylase were studies in detail. All oligonucleotide primers were designed based on EST sequences surrounding SNP regions of a known genotype (Shepody). The negative control was the nonreverse transcribed RNA. The amplicons ranged in size between $100-300 \mathrm{bp}$, and the Tm of the PCR products were estimated to be less than $95^{\circ} \mathrm{C}$ to ensure the observation of the entire scope of melting curves.

\section{Nucleic acid isolation}

Plant tissues were immediately frozen in liquid nitrogen and kept at $-80^{\circ} \mathrm{C}$. Total RNA was isolated using the RNeasy plant mini kit (Qiagen, Mississauga, ON) in combination with DNase treatment using the RNase-free DNase kit (Qiagen $\mathrm{GmbH}$, Hilden, Germany) according to the manufacturer's instruction.

\section{PCR conditions and HRM analysis}

Reverse transcription was carried out with $1 \mu \mathrm{g}$ of total RNA with the Retroscript kit at $50^{\circ} \mathrm{C}$ for one hour and $92^{\circ} \mathrm{C}$ for $5 \mathrm{~min}$, following manufacturer's instruction to prepare cDNA (Stratagene, La Jolla, CA). All of amplicons were amplified from potato cDNA in $10 \mu \mathrm{PCR}$ reactions containing $20 \mathrm{ng}$ cDNA template, PCR buffer $(1 \times), 1 \mathrm{U}$ of Taq polymerase (Invitrogen, Burlington, ON), $2 \mathrm{mM} \mathrm{MgCl}_{2}$, $1 \mathrm{mM}$ each of dATP, dCTP, dTTP and dGTP, $1 \mu$ of LC Green Plus (Idaho Technology, Salt Lake City, UT) and 20

Table 1. List of primers used to screen various tissues for the tissue- and treatment-specific cDNAs.

\begin{tabular}{lll}
\hline Primer name & Gene & Sequence \\
\hline CC1533A & ADP-glucose pyrophosphorylase & CC1533A-L: ACAAAGACAACGTTCAAGAAG \\
CA548A & Acid invertase & CA548A-L: AGGACAGTGCTTTACGACAA \\
& CA548A-R: CTCTGCAGCTGAGTCAACA \\
CA548B & Acid invertase & CA548B-L: ATTGAAGCAGATCATGTAGG \\
CP7079A & Glutamic acid decarboxylase & CP7079A-L: CTAACGTCTCAGTTGTGGAC \\
& CP7079A-R: CTTAACCATGTCATCTCCCAT \\
CA35A & Invertase inhibitor & CA35A-L: CACATGTCGATTCCCCAAT \\
CA35B & CA35A-R: GTCGTTTTCATTCCTACGT \\
& Invertase inhibitor & CA35B-L: TGGGAAAAGGCACGCC \\
CP96 & & CP96-L: CACTTGGCAAATCTACTCCG \\
& Sucrose synthase & \\
\hline
\end{tabular}


pmol of the primers. Primers were synthesized according to the sequences designed for SNPs in Shepody ESTs (Griffiths et al. http://10.110.16.26/SNP/snp.html). PCR amplifications were performed in a DNA Thermo-cycler (MJ Research Inc., Scarborough, ON) programmed for 41 cycles of $1 \mathrm{~min}$ at $95^{\circ} \mathrm{C}, 1 \mathrm{~min}$ at $50-65^{\circ} \mathrm{C}$ and $1 \mathrm{~min}$ at $72^{\circ} \mathrm{C}$. The PCR experiments were repeated at least once. Following amplification, the melting acquisition was performed on a LightScanner instrument (Idaho technology). Melting curve analysis was carried out with LightScanner software (version 2.0). Selected amplicons were purified with QIAquick PCR purification kit (Qiagen, Mississauga, ON) and directly sequenced by using gene specific primers with $\mathrm{ABI}$ Prism 3100 Genetic Analyzer facilitated in Institut de recherches cliniques de Montreal (IRCM; Montreal, QC) and Research Productivity Council (Fredericton, NB). Sequence graphs were visualized using the BioEdit program (Hall, 2004, http://www.mbio. ncsu.edu/BioEdit/bioedit.html). ClustalX2 was used to align the sequences and to generate Bootstrap-1000 NJ phylogeny trees. The LightScanner data were normalized by both local (local background value was subtracted from the intensity value of sample) and global metrics.

\section{Results}

\section{Correlation between HRM curve characteristics and transcript properties in different potato tissues}

All the 7 pairs of primers listed in Table 1 worked for the reverse transcription PCR (RT-PCR) and for the generation of HRM curves in the test stage of the primer using a few samples (data not shown). Full experiments were conducted only using 75 tissue-primer combinations, which resulted from PCR amplification with only five pairs of primers and 15 organs/tissues of the potato variety Shepody. The 5 primer pairs were derived from the cDNA sequences of acid invertase (EC 3.2.1.26), invertase inhibitor (two pairs), ADP glucose pyrophosphorylase (AGPase; EC 2.7. 7.27), and sucrose synthase (EC 2.4.1.13). HRM analysis of these four genes in the various potato tissues from the variety Shepody revealed unique patterns of HRM curves. All four of these assayed genes contained more than one sequence variants in these different organs and tissues. Figs 1 and 4 showed the cDNA analyzed with two pairs of the primers designed for the acid invertase (CA548B) and the invertase inhibitor (CA35B) genes.

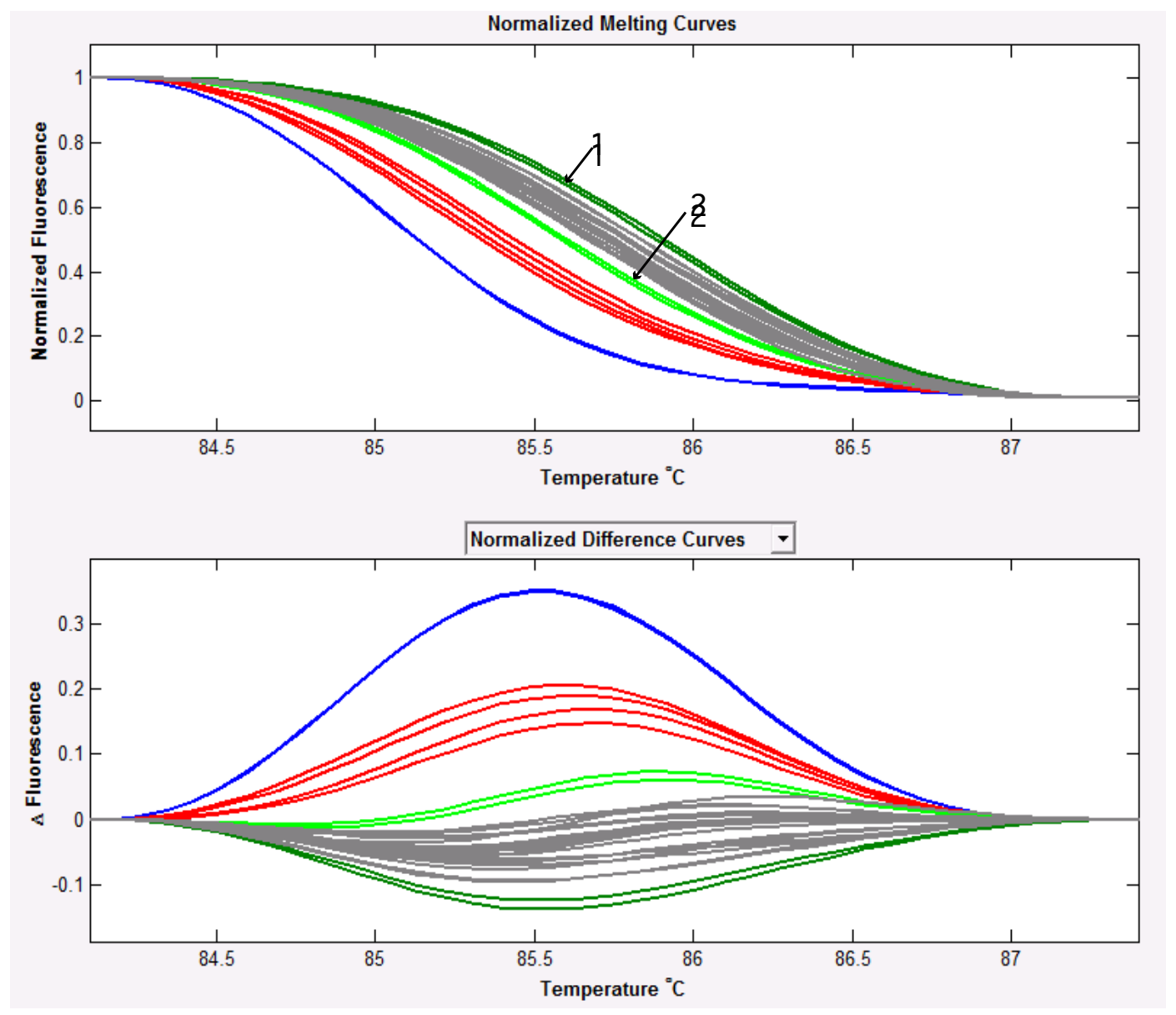

Fig. 1. High resolution melting curves of allelic expression variants of the invertase inhibitor gene locus (primer pair CA35B). Variety; Shepody; dark green curves: Young roots; light green curve: Young stems and old leaves; grey curves: Fruit, petiole, stolons, young tuber, mature tuber, skin of tuber, cortex, vascular ring and perimedullar; red curves: Shoot tip and young leaves; blue curves: Open flower; not shown. The PCR reactions for each tissue were performed in duplicate. Melting curve normalization was carried out with LightScanner software on the LightScanner (Idaho Inc., UT, USA). 


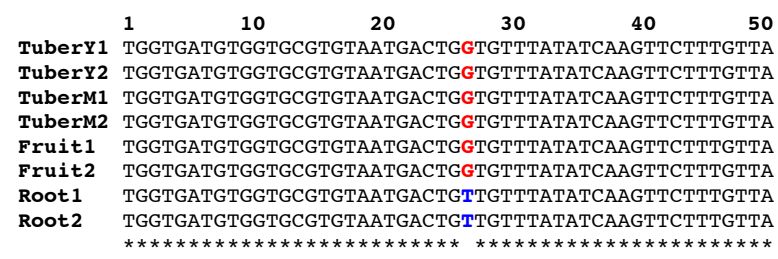

TuberY1 AAACATCAAAGTTGTGTGTTGACCAAACTGTTTGGAAAGTTAATCATGAA TuberY2 AAACATCAAAGTTGTGTGTTGACCAAACTGTTTGGAAAGTTAATCATGAA TuberM1 AAACATCAAAGTTGTGTGTTGACCAAACTGTTTGGAAAGTTAATGATGAA TuberM2 AAACATCAAAGTTGTGTGTTGACCAAACTGTTTGGAAAGTTAATGATGAA Fruit1 AAACAACAAAGTTGTGTGTTGACCAAACTGTTTGGAAAGTTAATAATGAA Fruit2 AAACAACAAAGTTGTGTGTTGACCAAACTGTTTGGAAAGTTAATAATGAA Root 1 AAACAACAAAGTTGTGTGTTGACCAAACTGTTTGGAAAGTTAATGATGAA AAACAACAAAGTTGTGTGTTGACCAAACTGTTTGGAAAGTTAATGATGAA

TuberY1 CAGTTGGTGGTAACTGGTGGTAACGTAGGAAATGAAAACGACATCTTCAA TuberY2 CAGTTGGTGGTAACTGGTGGTAACGTAGGAAATGAAAACGACATCTTCAA TuberM1 CAGTTGGTGGTAACTGGTGGTAACGTAGGAAATGAAAACGACATCTTCAA TuberM2 CAGTTGGTGGTAACTGGTGGTAACGTAGGAAATGAAAACGACATCTTCAA Fruit2 CAGTTGGTGGTAACTGGTGGTAACGTAGGAAATGAAAACGACATCTTCAA Root1 CAGTTGGTGGTAACTGGTGGTAAGGTAGGAAATGAAAACGACATCTTCAA Root2 CAGTTGGTGGTAACTGGTGGTAAGGTAGGAAATGAAAACGACATCTTCAA

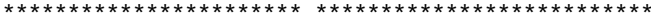

TuberY1 GATCAAGAAAACTGATTTGGTGATACCAGG---TATGAAAAATGTATACA TuberY2 GATCAAGAAAACTGATTTGGTGATACCAGG---TATGAAAAATGTATACA TuberY2 GATCAAGAAAACTGATTTGGTGATACCAGG---TATGAAAAATGTATACA
TuberM1 GATCAAGAAAACTGATTTGGTGATACCAGG---TATGAAAAATGTATACA TuberM1 GATCAAGAAAACTGATTTGGTGATACCAGG---TATGAAAAATGTATACA
TuberM2 GATCAAGAAAACTGATTTGGTGATACCAGG---TATGAAAAATGTATACA Fruit1 GATCAAGAAAACTGACTTGGTGATACCAGG---TATGAAAAATGTATACA Fruit2 GATCAAGAAAACTGACTTGGTGATACCAGG---TATGAAAAATGTATACA Root1 GATTATGAAAACTGACTTGGTGACACCAGGAGGTTCCAAATATGTATACA Root2 GATTATGAAAACTGACTTGGTGACACCAGGAGGTTCCAAATATGTATACA

Fig. 2. 'Shepody' cDNA sequence alignments of the most abundantly expressed variants (alleles). The primer (CA35B) used to screen each tissue was derived from invertase inhibitor. The purified amplicons were sequenced by an ABI Prism 3100 Genetic Analyzer. *: Consensus sequences among the allele transcripts.

The distinction of the melting curves was also confirmed by direct sequencing of RT-PCR amplicons. The sequences of some amplicons in several organs and tissues (e.g., Fig. 1: young-stem-CA35B) could not be defined because of the interference of non-ignorable basal expression from other polymorphic alleles or paralogs; However, there was a dominant variant in each sample at most times. It is known that the melting temperatures of different base pairs follow the order of CG>AT deletion and that a mixture of transcripts of the two would bring the melting temperature of the PCR products towards the mean value. Therefore, in most cases, HRM cures can suggest whether it is the higher Tm allele or the low Tm allele being the most actively expressed one in each RNA sample and can monitor whether the most active allele is a different one at different developmental stages, without the actual sequencing of the PCR products, as long as the genomic sequence of the SNP region is known.

HRM cures can reflect the characteristics of most abundant transcripts in multiple sample comparisons and can detect the allelic variation dynamics. Several PCR products from the heterozygous tetraploid potato variety Shepody were sequenced (Fig. 2) and a phylogenetic tree (Fig. 3) was generated. The HRM curves (Fig. 1) gave very similar distribution, reflecting well the allele positions on the phylogeneic tree (Fig. 3). There are four alleles detected for this invertase inhibitor gene locus (Fig. 2). The amplicons from root cDNAs had a small insert of three

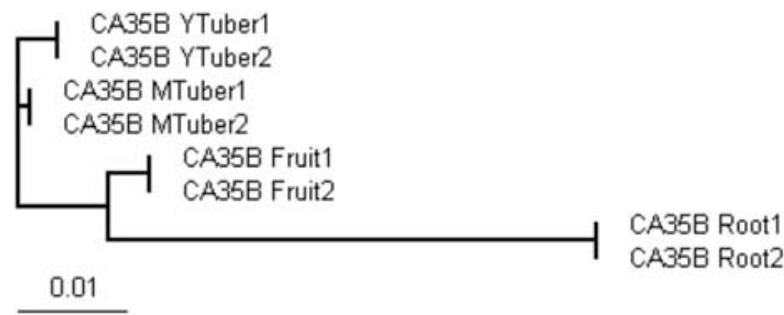

Fig. 3. Sequence-based phylogeny tree of the major transcripts detected by RT-PCR using the invertase inhibitor primer pair CA35B and RNA of various tissues. The scale bar represents an evolutionary distance of 0.01 nucleotide substitution per position.

bases and therefore were expected to have a highest Tm value than the cDNA amplicons from the other tissues and organs. Transcripts in young tubers, mature tubers, and fruits were different from each other but more or less similar (Fig. 2), compared to their differences with the root expressed variant allele. The phylogenetic tree showed that the root cDNA variant was considerably different from the cDNA sequences from the tuber and fruit tissues. The HRM curves perfectly reflected this difference in the phylogenetic tree and showed a particularly separation of the HRM curves of roots (dark green curves) from the curves for these tubers and fruits (grey curves in Fig. 1). In addition to this positional separation between the HRM curves and phylogenic tree, the HRM curves also indicated the difference of $\mathrm{Tm}$ value between the amplicons (Fig. 1 top panel). Therefore, the simple HRM assay can reflect well the sequence characteristics of the transcripts expressed from the alleles at the same locus.

\section{Sensitive reflection of HRM curves to the activity ratio between alleles}

In the analysis of the acid invertase (CA548B), the HRM curves showed a clear difference between the young roots and other tissues (stolons, mature tubers, and vascular ring tissues) (Fig. 4). The cDNA curves of young roots showed a higher Tm value by about $0.5^{\circ} \mathrm{C}$ (Fig. 4). However, the DNA sequence reading from direct sequencing of the RT-PCR products did not show the expected polymorphism at the T/C SNP (the bold T on the right side of Fig. 5). There is one base difference in one of the sequencing repeats of vascular cDNA (the C/A SNP on the left side of Fig. 5), but did not have the same reading in the other repeat sequencing and did not solve the question why only the root HRM showed a higher Tm value. To solve this puzzle, we visually compared the raw sequence graphs between cDNA sequences from different tissues (Figs 6 and 7). It was found that the $\mathrm{C}$-allele was expressed only at the nearly background level (Fig. 6) for the T/C SNP marked at right side in Fig. 5. However, there was a C/A SNP (the marked SNP at the left side in Fig. 5) at approximately the sequence position 61 in the PCR product sequences (Fig. 7). Both $\mathrm{C}$-allele and A-allele were expressed in all the tissues but the activity ratio is different. In the young roots, most transcripts are from the C-allele, and very little from the A-allele (Fig. 7 left panel); whereas, in other tissues the 


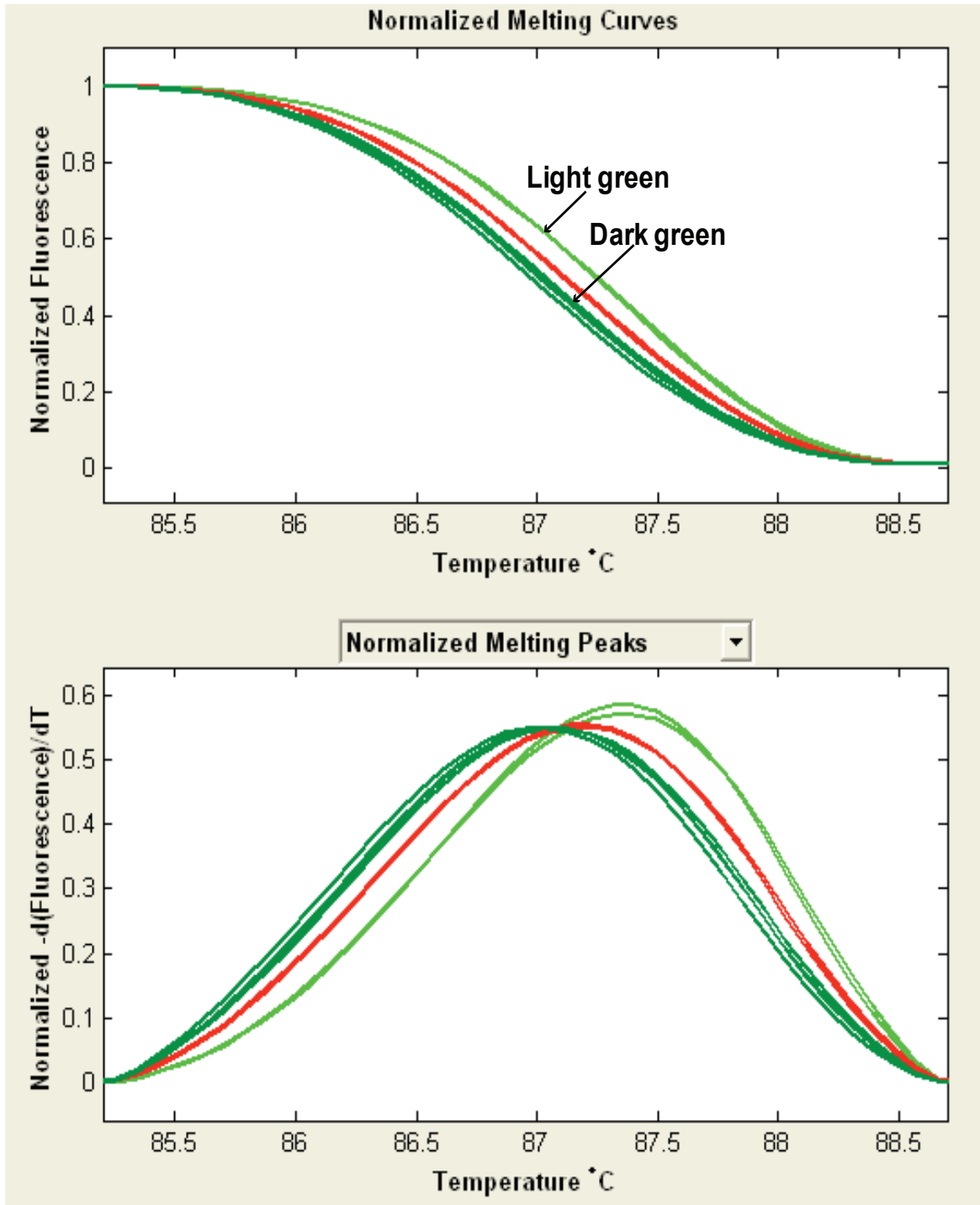

Fig. 4. High resolution melting curves of a SNP region (CA548B) of an acid invertase locus. Light green curve (marked by the arrow): Young roots; red curve: Stolons; dark green curves: Mature tuber and vascular ring. The PCR reactions for a tissue were amplified in duplicate. Melting curve normalization was carried out with LightScanner software on the LightScanner (Idaho Inc., UT). Note that the HRM curves of the two repeats of each tissue are very similar and that young root curves are different from the rest.

\begin{tabular}{|c|c|}
\hline Y.Root1 & САAACGCTATCTGAGCTAACGCCAGTTTACTTCTACATTTCTAAAGGAGCTGATGGTCGAGC \\
\hline Y.Root2 & CAAACGCTATCTGAGCTAACGCCAGTTTACTTCTACATTTCTAAAGGAGCTGATGGTCGAGC \\
\hline Stolon2 & САAАCGCTATCTGAGCTAACGCCAGTTTACTTCTACATTTCTAAAGGAGCTGATGGTCGAGC \\
\hline M.Tuber1 & САAACGCTATCTGAGCTAACGCCAGTTTACTTCTACATTTCTAAAGGAGCTGATGGTCGAGC \\
\hline M.Tuber2 & CAAACGCTATCTGAGCTAACGCCAGTTTACTTCTACATTTCTAAAGGAGCTGATGGTCGAGC \\
\hline Vascu 1 & САAАCGCTATCTGAGCTAACGCCAGTTTACTTCTACATTTCTAAAGGAGCTGATGGTCGAGC \\
\hline Vascu2 & САAAAGCTATCTGAGCTAACGCCAGTTTACTTCTACATTTCTAAAGGAGCTGATGGTCGAGC \\
\hline
\end{tabular}

Fig. 5. Sequence alignments (CDNA) showing the C/A SNP and T/C SNP region of the most abundantly expressed variants (alleles) of the acid invertase locus (primer CA548B) sequenced directly from RT-PCR products. Potato variety: Shepody. *: Consensus sequences among the allele transcripts. Note that the cDNA sequences readings of vascular tissue RT-PCR products are different; one is $\mathrm{C}$, and the other reading is $\mathrm{A}$. 
i6 Yuan et al.

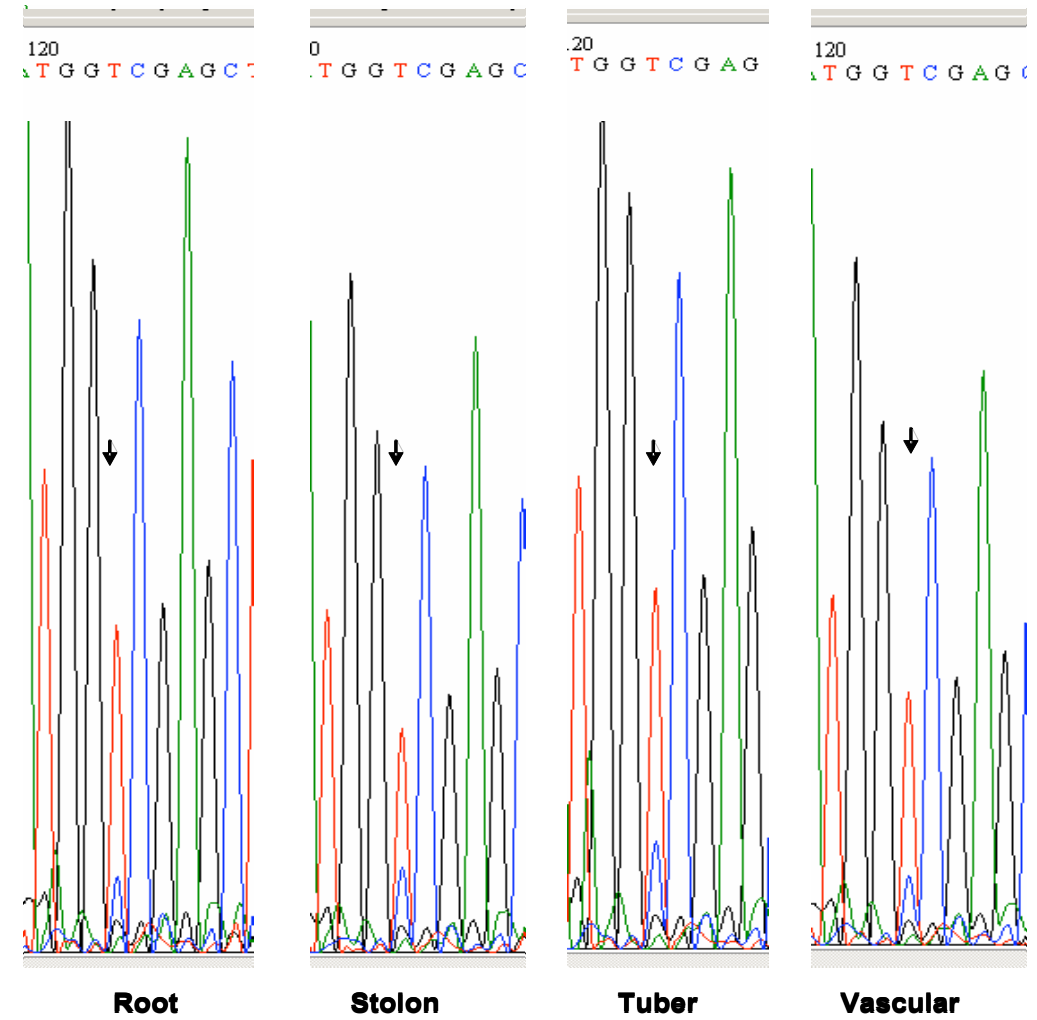

Fig. 6. Part of the raw CDNA sequence files of the targeted T/C SNP region of the abundantly expressed variants (alleles) at the acid invertase locus (primer CA548B) sequenced directly from RT-PCR products. Potato genotype: Shepody. Note that the C allele (blue peak at the SNP) transcript was at low abundance in all the four types of tissues and therefore is unlikely to influence the HRM curves significantly.

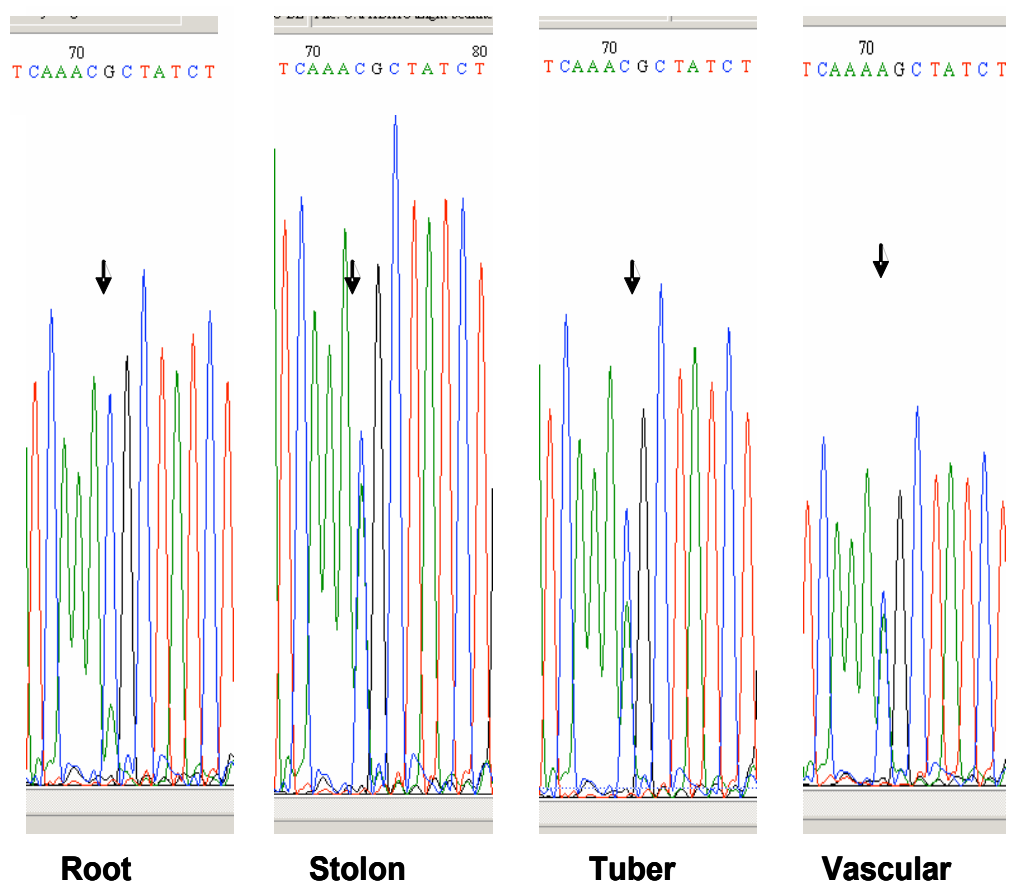

Fig. 7. Part of the raw cDNA sequence files of the C/A SNP region of the abundantly expressed variants (alleles) at the acid invertase locus (primer CA548B) sequenced directly from RT-PCR products. Potato genotype; Shepody. Note that in the cDNA sequence from vascular tissues (the right panel), the amplicon at the SNP read as the A allele by the sequencer, but actually both the C allele (blue peak at the marked SNP) and A allele accumulated to approximately the same abundances. 
transcript abundance difference between the two alleles is much smaller (the right 3 panels in Fig. 7). Since the downstream SNP (T/C) was only expressed minimally, the HRM difference should be mainly from this upstream C/A SNP. In conclusion, the HRM curves reflected well the activity ratio between alleles and showed which allele is more actively expressed for a SNP.

\section{Detection of allelic expression evolution in tubers during cold storage by HRM assay}

To assess the time course expression, the transcripts of tubers during cold storage using the AGPase gene locus (primer CC1533A) were measured. The expression activity shifted from a higher melting curve (day 0 and day 2 of storage) to a low melting curve allele (day 13 and day 30 of storage) among tubers of the low sugar content variety Atlantic during the $7^{\circ} \mathrm{C}$ cold storage (Fig. 8: left panel); whereas there was no such a clear shift in the higher sugar content variety Superior (Fig. 8: right panel). The time course also fit well with results from real time PCR (data not shown) but the Lightscanner could identify allelic variants much easily. Therefore, the high-resolution melting curve assay yields complementary and novel information for potato gene expression and demonstrates the power of the high-resolution melting curve method. Although more research is required to investigate whether the HRM curve shift in these varieties is related to the sugar contents in the tubers, the experiment indicates that HRM assay can monitor allelic expression during cold storage and detect differences among potato varieties in their response to cold storage at the transcript abundance level.

\section{Discussion}

Sensitivity and reproducibility are crucial parameters for all analyses of gene expression. The improved reliability of the LightScanner platform for transcript abundance measurement is mainly derived from the use of an improved simple RT-PCR analysis that does not require fluorescently labeled probes. The LightScanner platform only needs a small amount of target solution for the assay (Wittwer et al., 2003; Herrmann et al., 2006). For example, nano-scale aliquots of template in the $10 \mu \mathrm{l}$ of total PCR reaction with one amplification target per tube was performed in parallel in a 96-well-plate format and generated repeatable results. These advantages will enable high throughput screenings. For a direct comparison of various tissues, duplicates or triplicates from different samples can be assayed simultaneously in the 96-well format, and targeted amplicons were accurately determined and duplicated. The technology is sensitive enough to accurately detect the presence of allelic cDNA variants of a gene from various tissues. Significant differences between the treatments were observed between samples.

In the LightScanner software (Idaho Technology Inc, Salt Lake City, UT), there are a number of convenient methods to view and analyze the data, including normalized melting curves and normalized difference curves. These analyses are to highlight differences between individual
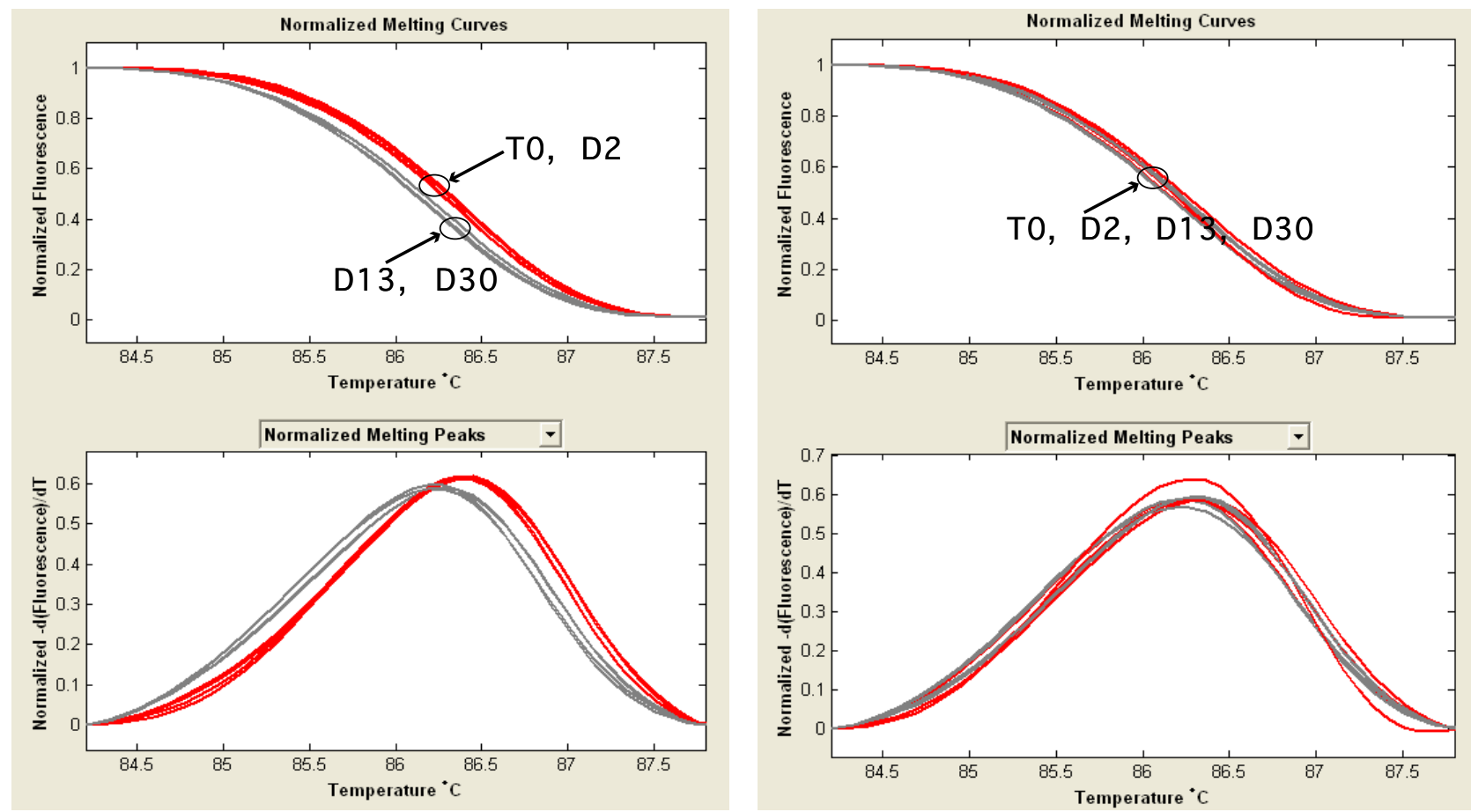

Fig. 8. Expressed dynamics of the ADP glucose pyrophosphorylase gene locus (primer pair CC1533A) gene. Left panel; potato genotype Atlantic. Right panel; potato genotype Superior. Red curves; day 0 (before storage) and day 2 at the start of cold $7^{\circ} \mathrm{C}$ storage. Grey curves; after 13 days and 30 days of $7^{\circ} \mathrm{C}$ storage treatments. The HRM assay for the time course study was duplicated. Note that the expression activity shifted to low melting alleles of the SNP during storage of 'Atlantic' tubers; whereas there was no such a shift in 'Superior'. 
curves and their baseline. The approach performed here, using unlabeled primers and LC Green, was less expensive than the commonly used fluorescence dyes. Because of its flexibility in experimental design and straightforward way of producing many replications, the direct evidence that the LightScanner platform was sensitive enough to resolve allelic expression differences among various tissues was simple to achieve. The protocols presented here are reliable and easy to handle, compared with various other gene expression analysis methods such as a realtime RT-qPCR method (Nolan et al., 2006), although each protocol has its advantages and disadvantages. This simple platform based on the melting temperature property of cDNA visualizes allelic variants spatially and temporally and assist pursuing each allele's function.

The molecular markers derived from genomic DNA or cDNA derived amplicons and the primers used here segregated in our mapping populations (Li et al., 2005) and can also be directly used for mapping purpose (data not shown). Conventionally, amplicons from different alleles of a known gene cannot be visually differentiated by regular RT-PCR if there is only one or a few nucleotides difference between amplicons. HRM technology largely solved this problem and therefore should be useful for QTL mapping and association genetic analysis with informative, expressed markers, a type of functional allele markers.

The LightScanner HRM system can also use an oligo-probed approach to distinguish two SNPs in the same region amplified by the same pair of primers (Idaho Technology Inc, Salt Lake City, UT). While the oligoprobe approach can give additional useful information in our recent experiments (AGPase, data not shown, unpublished), this non-probe approach is simpler for manipulation and analysis. This simple, fast approach is capable of generating useful information very effectively as demonstrated in this study. The method is so sensitive probably because PCR amplicon regions are very short (150-250 bp) and so closely-linked SNPs behave very similarly, unless a rare genetic recombination occurs within such a short region. This study used a PCR-product sequencing approach to verify the HRM results. However if a database was available for genomic SNPs or cDNA SNPs and their melting temperatures of the SNP regions, the cDNA HRM data with or without the oligo probes could be used as functional allele activity (FAA) markers to sensitively detect the dominantly expressed allele and the transcript abundance ratio between alleles. It is also likely that FAA markers can be converted to functional allele genomic (FAG) markers.

\section{Acknowledgements}

We thank S. Whitney for the assistance in using LightScanner, X. Liu for providing some RNA samples, Drs. O. Neyret-Djossou and R. Ritchie for PCR amplicon sequencing, and Dr. D. DeKoeyer for useful discussion and for critical reading of an early version of this manuscript. This research was funded by AAFC A-base and the Canada/NB Embracing Innovation in Agriculture and Agri-Food Program (EIA) through NB Potato Agency (R. Gareau).

\section{References}

Alwine, J.C., Kemp, D.J., and Stark, G.R. (1977) Method for detection of specific RNAs in agarose gels by transfer to diazobenzyloxymethyl-paper and hybridization with DNA probes. Proc. Natl. Acad. Sci. U.S.A. 74, 53505354.

Chateigner-Boutin, A.L., and Small, I. (2007) A rapid highthroughput method for the detection and quantification of RNA editing based on high-resolution melting of amplicons. Nucl. Acids Res. 35, e114.

Flinn, B., Rothwell, C., Griffiths, R., Lague, M., DeKoeyer, D., Sardana, R., Audy, P., Goyer, C., Li, X.Q., WangPruski, G., and Regan, S. (2005) Potato expressed sequence tag generation and analysis using standard and unique cDNA libraries. Plant. Mol. Biol. 59, 407433.

Foolad, M.R., and Lin, G.Y (1998) Genetic analysis of low-temperature tolerance during germination in tomato, Lycopersicon esculentum Mill. Plant Breed. 117, 171-176.

Guo, M., Rupe, M.A., Yang, X., Crasta, O., Zinselmeier, C., Smith, O.S., and Bowen, B. (2006) Genome-wide transcript analysis of maize hybrids: allelic additive gene expression and yield heterosis. Theor. Appl. Genet. 113, 831-845.

Herrmann, M.G., Durtschi, J.D., Bromley, L.K., Wittwer, C.T., and Voelkerding, K.V. (2006) Amplicon DNA melting analysis for mutation scanning and genotyping: Cross-platform comparison of instruments and dyes. Clin. Chem. 52, 494-503.

Herrmann, M.G., Durtschi, J.D., Wittwer, C.T., and Voelkerding, K.V. (2007) Expanded instrument comparison of amplicon DNA melting analysis for mutation scanning and genotyping. Clin. Chem. 53, 1544-1548.

Howell, W.M., Jobs, M., and Brookes, A.J. (2002) iFRET: An improved fluorescence system for DNA-melting analysis. Genome Res. 12, 1401-1407.

lqbal, M.J., Yaegashi, S., Ahsan, R., Shopinski, K.L., and Lightfoot, D.A. (2005) Root response to Fusarium solani f. sp. glycines: Temporal accumulation of transcripts in partially resistant and susceptible soybean. Theor. Appl. Genet. 110, 1429-1438.

Jeong, S., Hahn, Y., Rong, Q., and Pfeifer, K. (2007) Accurate quantitation of allele-specific expression patterns by analysis of DNA melting. Genome Res. 17, 1093-1100.

Journot-Catalino, H., Somssich, I.E., Roby, D., and Kroj, T. (2006) The transcription factors WRKY11 and WRKY17 act as negative regulators of basal resistance in Arabidopsis thaliana. Plant Cell 18, 3289-3302.

Kugita, M., Yamamoto, Y., Fujikawa, T., Matsumoto, T., and Yoshinaga, K. (2003) RNA editing in hornwort chloroplasts makes more than half the genes functional. Nucl. Acids Res. 31, 2417-2423.

Li, X.Q., De Jong, H., De Jong, D.M., and De Jong, W.S. (2005) Inheritance and genetic mapping of tuber eye depth in cultivated diploid potatoes. Theoretical and Applied Genetics 110, 1068-1073.

Meyers, B.C., Galbraith, D.W., Nelson, T., and Agrawal, V. (2004) Methods for transcriptional profiling in plants. Be fruitful and replicate. Plant Physiol. 135, 637-652. 
Montgomery, J., Wittwer, C.T., Palais, R., and Zhou, L. (2007) Simultaneous mutation scanning and genotyping by high-resolution DNA melting analysis. Nat. Protoc. 2, 59-66.

Nolan, T., Hands, R.E., and Bustin, S.A. (2006) Quantification of mRNA using real-time RT-PCR. Nat. Protoc. 1, 1559-1582.

SantaLucia Jr, J. (1998) A unified view of polymer, dumbbell, and oligonucleotide DNA nearest-neighbor thermodynamics. Proc. Natl. Acad. Sci. U.S.A. 95, 1460-1465.

Schenk, P.M., Kazan, K., Wilson, I., Anderson, J.P., Richmond, T., Somerville, S.C., and Manners, J.M. (2000) Coordinated plant defense responses in Arabidopsis revealed by microarray analysis. Proc. Natl. Acad. Sci. U.S.A. 97, 11655-11660.
Syvanen, A.C. (2001) Accessing genetic variation: Genotyping single nucleotide polymorphisms. Nat. Rev. Genet. 2, 930-942.

Velculescu, V.E., Zhang, L., Vogelstein, B., and Kinzler, K.W. (1995) Serial analysis of gene expression. Science 270, 484-487.

Wittwer, C.T., Reed, G.H., Gundry, C.N., Vandersteen, J.G., and Pryor, R.J. (2003) High-resolution genotyping by amplicon melting analysis using LCGreen. Clin. Chem. 49, 853-860.

Zhao, B., Ardales, E.Y., Raymundo, A., Bai, J., Trick, H.N., Leach, J.E., and Hulbert, S.H. (2004) The avrRxo1 gene from the rice pathogen Xanthomonas oryzae pv. oryzicola confers a nonhost defense reaction on maize with resistance gene Rxo1. Mol. Plant Microbe Interact. 17, 771-779. 


\section{Further Reading}

Caister Academic Press is a leading academic publisher of advanced texts in microbiology, molecular biology and medical research. Full details of all our publications at caister.com

- MALDI-TOF Mass Spectrometry in Microbiology Edited by: M Kostrzewa, S Schubert (2016) www.caister.com/malditof

- Aspergillus and Penicillium in the Post-genomic Era Edited by: RP Vries, IB Gelber, MR Andersen (2016) www.caister.com/aspergillus2

- The Bacteriocins: Current Knowledge and Future Prospects Edited by: RL Dorit, SM Roy, MA Riley (2016)

www.caister.com/bacteriocins

- Omics in Plant Disease Resistance Edited by: V Bhadauria (2016) www.caister.com/opd

- Acidophiles: Life in Extremely Acidic Environments Edited by: R Quatrini, DB Johnson (2016) www.caister.com/acidophiles

- Climate Change and Microbial Ecology: Current Research and Future Trend

Edited by: J Marxsen (2016)

www.caister.com/climate

- Biofilms in Bioremediation: Current Research and Emerging Technologies

Edited by: G Lear (2016)

www.caister.com/biorem

- Microalgae: Current Research and Applications Edited by: MN Tsaloglou (2016) www.caister.com/microalgae

- Gas Plasma Sterilization in Microbiology: Theory, Applications, Pitfalls and New Perspectives Edited by: H Shintani, A Sakudo (2016) www.caister.com/gasplasma

- Virus Evolution: Current Research and Future Directions Edited by: SC Weaver, M Denison, M Roossinck, et al. (2016) www.caister.com/virusevol

- Arboviruses: Molecular Biology, Evolution and Control Edited by: N Vasilakis, DJ Gubler (2016) www.caister.com/arbo

- Shigella: Molecular and Cellular Biology Edited by: WD Picking, WL Picking (2016) www.caister.com/shigella

-Aquatic Biofilms: Ecology, Water Quality and Wastewater Treatment

Edited by: AM Romaní, H Guasch, MD Balaguer (2016)

www.caister.com/aquaticbiofilms

- Alphaviruses: Current Biology

Edited by: S Mahalingam, L Herrero, B Herring (2016)

www.caister.com/alpha

- Thermophilic Microorganisms

Edited by: F Li (2015)

www.caister.com/thermophile
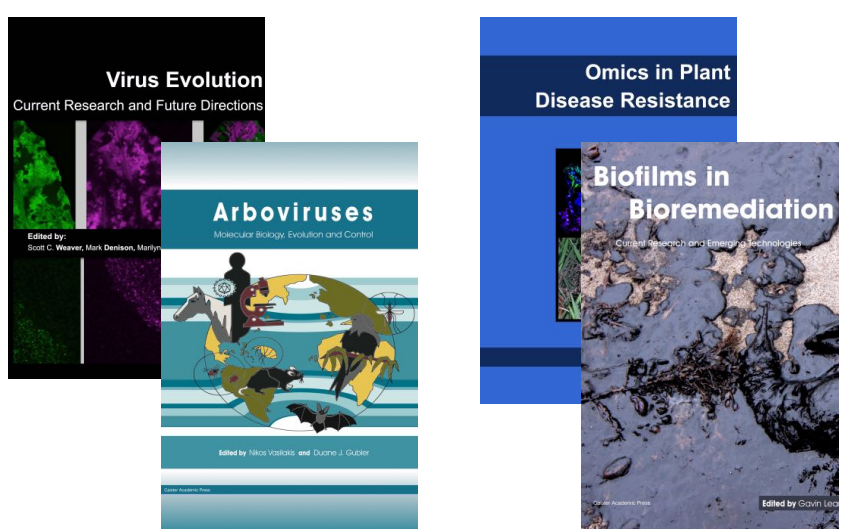
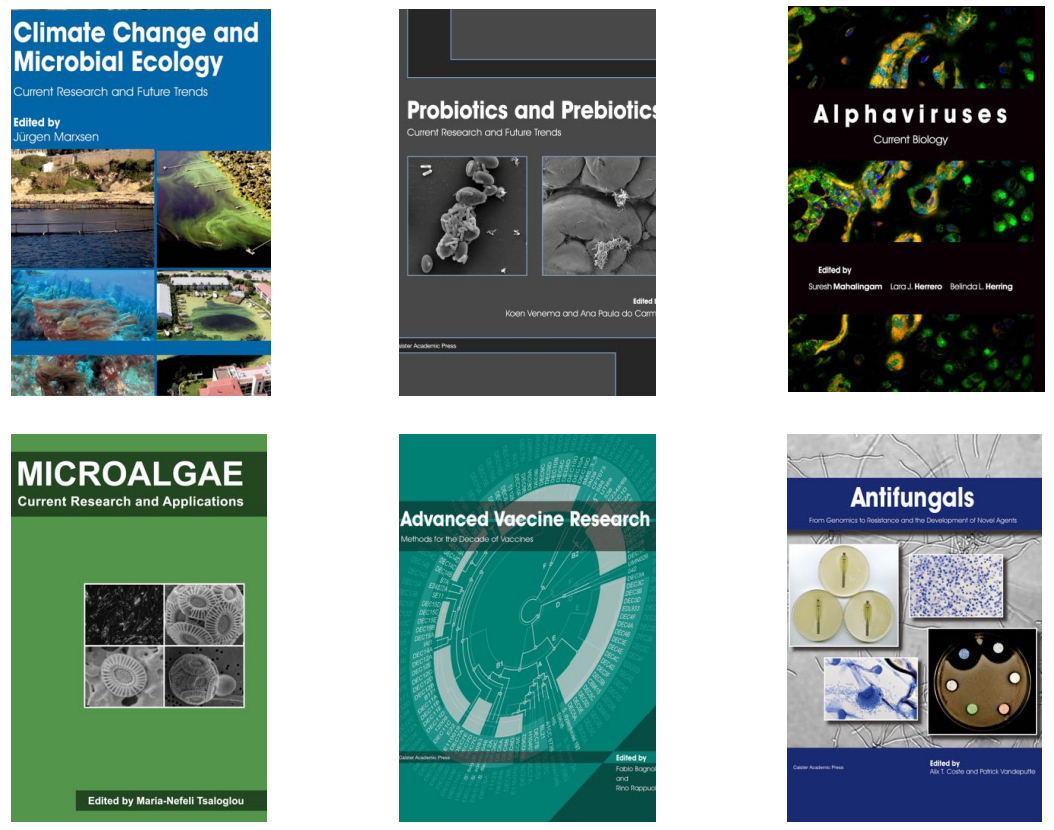

- Flow Cytometry in Microbiology: Technology and Applications Edited by: MG Wilkinson (2015) www.caister.com/flow

- Probiotics and Prebiotics: Current Research and Future Trends Edited by: K Venema, AP Carmo (2015) www.caister.com/probiotics

- Epigenetics: Current Research and Emerging Trends Edited by: BP Chadwick (2015) www.caister.com/epigenetics2015

- Corynebacterium glutamicum: From Systems Biology to Biotechnological Applications

Edited by: A Burkovski (2015)

www.caister.com/cory2

- Advanced Vaccine Research Methods for the Decade of Vaccines

Edited by: F Bagnoli, R Rappuoli (2015)

www.caister.com/vaccines

- Antifungals: From Genomics to Resistance and the Development of Novel Agents

Edited by: AT Coste, P Vandeputte (2015)

www.caister.com/antifungals

- Bacteria-Plant Interactions: Advanced Research and Future Trends Edited by: J Murillo, BA Vinatzer, RW Jackson, et al. (2015) www.caister.com/bacteria-plant

\section{- Aeromonas}

Edited by: J Graf (2015)

www.caister.com/aeromonas

- Antibiotics: Current Innovations and Future Trends

Edited by: S Sánchez, AL Demain (2015)

www.caister.com/antibiotics

- Leishmania: Current Biology and Contro Edited by: S Adak, R Datta (2015) www.caister.com/leish2

- Acanthamoeba: Biology and Pathogenesis (2nd edition) Author: NA Khan (2015)

www.caister.com/acanthamoeba2

- Microarrays: Current Technology, Innovations and Applications Edited by: Z He (2014)

www.caister.com/microarrays2

- Metagenomics of the Microbial Nitrogen Cycle: Theory, Methods and Applications

Edited by: D Marco (2014)

www.caister.com/n2 